\title{
Sobre las necesidades insatisfechas. Género y migraciones como factores de pobreza
}

\section{Miguel Ángel Mateo Pérez}

Universitat d'Alacant. Departament de Sociologia II

Ma.Mateo@ua.es

\section{Resumen}

En este trabajo se exponen diferentes puntos de vista sobre la pobreza y diversos mecanismos sociales que conducen a situaciones de empobrecimiento. En particular se analiza la dimensión de género en el estudio de la pobreza y se profundiza en las migraciones como un factor de posible empobrecimiento para el emigrado. Se expone el caso de la Comunidad Valenciana como referente espacial, aunque los modelos de explicación y análisis pueden referirse al conjunto de países ricos.

Palabras clave: desigualdad, pobreza, perspectiva de género, Comunidad Valenciana.

\section{Abstract. Needs and dissatisfaction. Gender and migrations like factors of poverty}

In this work we expose several points of view on poverty and diverse social mechanisms that they drive to situations of impoverishment. In particular the dimension of gender in the study of the poverty is analyzed and is fathomed in the migrations like a factor of possible impoverishment for the emigrated. The case of the Valencian Community is exposed like relating space, although the models of explanation and analysis could refer to the group of rich countries.

Key words: inequality, poverty, gender perspective, Valencian Region.

\section{Sumario}

1. Introducción 4. Factores de empobrecimiento de los inmigrantes en la Comunidad Valenciana

2. Investigaciones previas y cuestiones metodológicas 5. Conclusiones

3. Pobreza, migraciones, género Bibliografía

* Este trabajo es parte de la investigación financiada por el Instituto de la Mujer titulada Indicadores dinámicos para el estudio del empobrecimiento de las mujeres (Ref. IM-0003), dirigida por José María Tortosa (Universidad de Alicante). El autor quiere agradecer a Dana Zirpoli las discusiones sobre algunas de las cuestiones que aquí se plantean, aunque de los errores sea él el único responsable. 


\section{Introducción}

Los movimientos de población y en particular los procesos migratorios han sido estudiados con detalle por demógrafos, economistas y sociólogos desde hace ya bastante tiempo. Más recientemente, las investigaciones se han centrado en las implicaciones sociales que tienen dichos procesos, tanto desde un punto de vista local (Solé, 1988) como desde puntos de vista más globales o tocantes a la cuestión del sistema mundial (Castles, 1998; Casado y Simón, 1996; Pajares, 1998 y Malgesini, 1998, entre otros). Estos trabajos han ofrecido un marco apropiado para empezar a estudiar las migraciones vinculadas a otros procesos sociales. Las dimensiones demográficas son básicas para entender nuestras sociedades, pero su estudio no ha de desvincularse de otros. No entenderíamos las migraciones si no estudiamos los procesos económicos estructurales y coyunturales del sistema mundial. Como tampoco las entenderíamos sin estudiar los procesos de empobrecimiento (Tortosa, 1993). Y si es posible hablar de una creciente feminización de la pobreza, también podemos hablar en esos mismos términos de la tendencia creciente en la feminización de las migraciones. Como veremos, es posible ligar los fenómenos migratorios al empobrecimiento desde una perspectiva de género.

Con este trabajo perseguimos tres objetivos: 1) vincular teóricamente los conceptos de empobrecimiento y migraciones sirviéndonos del vínculo que nos ofrece el entender el empobrecimiento como la insatisfacción de las necesidades humanas básicas; 2) plantear los principales elementos estructurales que condicionan las migraciones y desencadenan la insatisfacción de las necesidades humanas de los emigrados en las sociedades receptoras, y 3) señalar algunos de estos elementos de forma empírica para la Comunidad Valenciana en la década de 1990.

Dividimos la exposición en cinco epígrafes generales. El primer epígrafe es la introducción que en este momento el lector está leyendo. En el segundo el lector encontrará los supuesto metodológicos de partida, estudios previos, fuentes y referencias empíricas. En el tercer epígrafe, el más amplio, nos centraremos en los elementos conceptuales básicos: construcción de los términos empobrecimiento y migraciones y sus características. Se añadirá la perspectiva de género como enfoque y estudiaremos las vinculaciones entre género, pobreza y migraciones. En el cuarto utilizaremos el contexto de la Comunidad Valenciana en los noventa como ejercicio empírico aplicado. Concluiremos con un quinto epígrafe en el que se resumirán las principales cuestiones tratadas en este trabajo.

\section{Investigaciones previas y cuestiones metodológicas}

\section{Investigaciones previas}

Hay suficientes investigaciones sobre los procesos migratorios como para que este trabajo se pudiera convertir en una sucesión de citas a trabajos rela- 
cionados. No es ése nuestro objetivo. Pero, como siempre en la investigación social, partimos de algunos que consideramos claves en el punto de partida de nuestro trabajo. Así, el trabajo de Giner y Salcedo (1976), que incide sobre las posibles causas múltiples de los fenómenos migratorios, al margen de la económica, es un buen punto de partida para la reflexión sociológica que en nuestro caso se completa con visiones más recientes (García Martín, 1997; Fambuena y Moya, 1997 y en particular Bodega y Cebrián, 1995). En otro orden de cosas, nuestras fuentes teóricas se acercan más a los textos que vinculan de alguna manera la pobreza o las desigualdades y las migraciones. Estudios de partida como los realizados por el Comité Económico y Social de la Unión Europea en 1993; o los elaborados por el Alto Comisionado de Naciones Unidas para los Refugiados (ACNUR, 1997), pasando por las consideraciones de Fielding (1997), Lipton (1997) y Guidi (1993). Ya más centrados en el ámbito de la Comunidad Valenciana, hay que destacar los trabajos de Gosálvez (1995) y los de Lacomba y Royo (1997). Estos últimos toman como elemento clave en sus discursos la vinculación entre pobreza (entendida la mayoría de las veces de forma exclusivamente económica) y los movimientos migratorios. Por último, tomamos como trabajos de referencia los que estudian los procesos de empobrecimiento con los migratorios desde (o utilizando) la perspectiva de género. Básicamente, Santamaría (1997), Serrano (1997), Bernstein y Shuval (1999), Gregorio (1998) (que analiza las variaciones en las relaciones de género que implican las migraciones), Hagan (1998) y Kofman y Sales (1998) (éste último lo tomaremos como referente de partida para las consideraciones que hagamos sobre género, empobrecimiento y migraciones).

\section{Cuestiones metodológicas}

Este estudio adopta dos perspectivas metodológicas. En primer lugar, construye teóricamente los conceptos con los cuales vamos a trabajar: pobreza y migraciones desde la perspectiva de género. Nos apoyaremos, desde esta óptica, en las investigaciones que se han desarrollado desde diferentes disciplinas en un ejercicio de síntesis en la definición de pobreza y en los procesos migratorios (definiciones, tipologías, causas, efectos). Para la vinculación entre los fenómenos estudiados no renunciamos a la utilización de datos empíricos. Son datos provenientes de diversas fuentes y reelaborados estadísticamente para estas páginas y cuyo ámbito general es el marco del Estado español, aunque se utilice como unidad de análisis la comunidad autónoma. Nos basaremos en datos de opinión pública procedentes de estudios del CIS, CIRES y ASEP y datos estadísticos procedentes del INE, IVIE y CCOO. Nos centraremos, para el trabajo empírico, más concretamente en la Comunidad Valenciana en la década de los noventa. Utilizaremos las correlaciones como estadísticos de asociación entre variables. Los cálculos se han realizado con SPSS V.9. 


\section{Pobreza, migraciones, género}

\subsection{Pobreza como insatisfacción de las necesidades humanas básicas}

Vamos a entender la pobreza como el proceso en el que las necesidades humanas consideradas básicas son involuntariamente insatisfechas de manera perseverante en el tiempo ${ }^{1}$. Esta afirmación, que responde a una perspectiva teórica con respecto a la pobreza cualitativamente distinta a las que se suelen adoptar incluso por la Unión Europea, tiene dos aspectos clave que trataremos de esclarecer inmediatamente: 1) por un lado existe una dificultad a la hora de conceptualizar las necesidades humanas y 2) la variable tiempo ha de recogerse en los análisis que se realicen de una manera explícita y fundamentada.

La misma afirmación presupone que existen factores ajenos o externos al individuo, grupo, familia..., y que son intrínsecos de la sociedad que impiden la satisfacción de las necesidades. De esta manera, la satisfacción autónoma de las necesidades de manera individual no se puede concebir (Casado, 1994).

La definición de necesidad que ofrece el diccionario de la Real Academia de la Lengua, señala algunas cuestiones que nos hacen pensar en la ambivalencia del término. En primer lugar: "todo aquello a lo cual es imposible substraerse, faltar o resistir; falta de las cosas que son menesteres para la conservación de la vida; falta continuada de alimento; especial riesgo o peligro que se padece y que necesita de pronto auxilio» (RAE, 1990: 948). Más concluyente es el significado único que le atribuye al término necesitado: «Adjetivo: pobre, que carece de lo necesario» (RAE, 1990: 949). Desde otro punto de vista, depende de la disciplina o materia que tomemos como referencia se van a definir de una manera o de otra qué son y qué características tienen las necesidades. Tomaremos la perspectiva sociológica, aunque no habría que desdeñar los aportes de la filosofía (Ferrater, 1983), la psicología (Dorsch, 1985; Maslow, 1979) o el derecho (Martín Mateo, 1996; Parada, 1995; Añón, 1994).

\subsubsection{Interpretaciones teóricas desde la sociología}

Generalmente el concepto necesidad se ha analizado desde la sociología con sentidos muy diferentes. Distinguiremos tres (Abercrombie, 1986) antes de pasar a una reelaboración teórica definitiva:

a) Como parte de la teoría de la motivación individual, en la que las acciones se explican haciendo referencia a las necesidades. Desde esta perspectiva, el concepto se acerca al de pulsión, empleado desde la psicología.

1. Evidentemente, ésta no es la única manera de aproximarse al concepto de pobreza. Sin embargo, ésta última se acerca más a una perspectiva muldimensional y dinámica. Tampoco se persigue medir la pobreza. Para estas cuestiones, ver Atkinson (1988) y Mateo y Penalva (2000). 
b) También la teoría funcionalista ha usado el término necesidad en un sentido diferente al que nosotros le estamos dando en estas páginas. Parsons habla de cuatro necesidades (imperativos funcionales) que el sistema necesita satisfacer para que sobreviva en el mismo.

c) Desde la perspectiva marxista también se ha estudiado el tema de las necesidades humanas. De este punto de vista, podemos extraer conclusiones útiles para nuestro estudio. Veamos a dos autores fundamentales.

Marcuse (1969: 35 y s.) señala dos tipos de necesidades: las falsas o artificiales (impuestas por determinados intereses sociales y cuya satisfacción se realiza a través del mercado) y las verdaderas, cuya satisfacción no se produce en el mercado. Las primeras se identifican con los términos deseo y consumo y son las que dominan en las sociedades capitalistas. Sin embargo, las segundas forman parte de lo que él llama «espacio residual». Desde el punto de vista que nos afecta en esta investigación, la distinción acertada entre necesidades falsas y verdaderas y sus relaciones, explica la existencia de países y grupos con una abundancia en la cobertura de las necesidades falsas y una insatisfacción de las verdaderas o básicas. En ese caso, estaríamos hablando de pobreza, aunque puede que no parezca, pero si existen situaciones de insatisfacción de necesidades verdaderas como la participación, estamos ante la pobreza. También esta teoría nos será útil a la hora de conceptualizar lo que otros autores han llamado «satisfactores» (Max-Neef, 1994) o "necesidades intermedias» (Doyal y Gough, 1994) y que se corresponden con las «necesidades falsas» en sentido amplio. Agnes Heller recoge el legado teórico de Marcuse y establece una tipología humanista de las necesidades humanas (Heller, 1978).

Las tres perspectivas ofrecen un resumen del material con el que la sociología ha ido trabajando con respecto a necesidades humanas y sociales. Las necesidades humanas son sociales e históricas, universales y objetivas. Esta afirmación significa muchas cosas que conviene analizar detenidamente:

a) Las necesidades son individuales en el sentido que son las personas como agentes individuales las que las sienten o padecen. Pero no es menos cierto que es en sociedad cuando esas necesidades se identifican como tales, se priorizan y se satisfacen. Desde nuestro punto de vista, las necesidades no se pueden tildar de sociales simplemente porque se realice un sumatorio de las mismas, como se suele decir desde la psicología. Así, las diferentes necesidades irán evolucionando en una línea histórica de tiempo o, por lo menos, así podría parecérnoslo. Hay necesidades humanas básicas que permanecen inmutables a lo largo de todos los periodos históricos y en todas las culturas. Parece ser que lo que evolucionan más bien son los satisfactores de esas necesidades.

b) Las necesidades humanas son universales, siguiendo el razonamiento anterior. Esta universalidad, discutida por algunos estudiosos del tema, quiere decir que existen necesidades humanas iguales en toda sociedad, en toda etnia y en todo periodo histórico, como decíamos. Tomando la clasificación de Doyal y Gough, podemos afirmar que las dos necesidades univer- 
sales humanas básicas se resumen en: salud física y autonomía ${ }^{2}$. Estas necesidades son objetivas, esto es, están visibles en la sociedad y son susceptibles de medición empírica. Nos alejamos, pues, de la consideración de necesidades meramente subjetivas cuyo único referente es el individuo. Para otros autores (Max-Neef y PNUD, por ejemplo), el catálogo de necesidades humanas básicas, universales y objetivas se amplía hasta números más importantes y más difíciles de manejar empíricamente.

El caso de Max-Neef y de sus seguidores, entre los que destaca Antonio Elizalde, es paradigmático. Distinguen, para clasificar las necesidades, entre necesidades existenciales (ser, tener, hacer, estar) y necesidades según categorías axiológicas (subsistencia, protección, afecto, entendimiento, participación, ocio, creación, identidad y libertad) (Max-Neef, 1994). Como se obser$\mathrm{va}$, sale una matriz con treinta y seis casillas, perfectamente inoperante aunque su marco teórico sea excepcional. Sin embargo, una de las cuestiones más importantes de la visión ofrecida por estos autores radica en la definición y sistematización de lo que ellos han llamado "satisfactores». Los satisfactores no son otra cosa que los mecanismos por los cuales las necesidades se satisfacen. Generalmente se suelen confundir los satisfactores con las verdaderas necesidades, generándose discursos como el que se refiere a la no limitación de las necesidades humanas (cuando los ilimitados son los satisfactores), generando a su vez un tipo de discurso político y científico sobre la no universalidad de las necesidades, cuando lo no universal son sus satisfactores. También se puede observar que son ellos el objeto de la publicidad y del mercado, que potencia su uso generando falsas necesidades gracias al deseo y al consumo. Además, conviene resaltar que existen satisfactores que inhiben la satisfacción de una auténtica necesidad.

A modo de resumen, para estudiar la pobreza desde el punto de vista de la insatisfacción de las necesidades humanas básicas, hay que tener presentes los siguientes puntos:

- Debemos tener en cuenta que las necesidades afectan al individuo, pero son generadas, definidas y satisfechas en el marco de una sociedad.

- Que son universales y objetivas, además de históricas.

- Que afectan a todos los aspectos de la vida social (economía, política, cultura, relaciones sociales ${ }^{3}$ ).

- Que las podemos sintetizar en salud física y autonomía.

2. Salud física se define en sentido negativo o de privación. Esta necesidad queda satisfecha cuando los individuos no padecen de manera prolongada una o más dolencias. Autonomía es la capacidad de elección entre dos opciones informadas y se fundamenta en el grado de comprensión que una persona tiene de sí misma y del entorno, la capacidad psicológica y las oportunidades objetivas (Doyal y Gough, 1994, cap. 4). Para una discusión de lo anterior, ver Aguiar (1996: 135-146) y Bouzada (1994).

3. Hay autores que señalan que el concepto de necesidad en la sociología desplaza al concepto de relación social (Rubí, 1991). 
- Que los satisfactores, que satisfacen las necesidades, muchas veces inhiben la satisfacción de las mismas, al generar un proceso en el cual algunos de estos satisfactores son confundidos como verdaderas necesidades.

\subsection{Las migraciones. Visiones desde la demografia y la estructura social}

\subsubsection{Definiciones, tipologías y causas de las migraciones}

Podríamos definir la migración como un cambio de residencia que implica la ruptura de la actividad laboral, social y cultural en el país de origen para intentar reanudarla en el país de destino (Weeks, 1984, cap. 7). Pese a que esta definición es muy amplia, nos permite ciertamente acotar el término con el que estamos trabajando. Descendamos al nivel de las definiciones y hagamos caso a las siguientes:

- Extranjero: se definiría en sentido negativo como aquél que carece de la nacionalidad española (Sagarra i Trias, 1991: 23).

— Inmigración: «acción o efecto de inmigrar» e inmigrar se define como «la llegada a un país para establecerse en él de los que estaban domiciliados en otro, diciéndose especialmente de los que han formado colonias o se domicilian en las ya formadas" (RAE).

- Inmigrado: «la persona que, en busca de trabajo, fija su residencia en un país distinto al suyo» (García, 1993: 13).

Desde el punto de vista del marco normativo de contexto con el que se traslada el inmigrante, tenemos que referirnos a otros dos conceptos clave:

1. Los legales son aquellos inmigrantes que en el país receptor cumplen una serie de características: empleo (con contrato), visado de trabajo, permiso de residencia... Estas condiciones varían según la legislación de cada país, si bien se ha hecho por norma común el establecer leyes de extranjería que se aplican con bastante dureza.

2. Los inmigrantes ilegales son aquéllos que no están empadronados y que no tienen ni contrato laboral ni permiso de residencia. Pese a lo que se diga, los episodios de inmigración ilegal son mucho más frecuentes que los de la legal. Quizás esto sea provocado por la singular particularidad del mercado de trabajo. Estas cuestiones las veremos más tarde.

Al hilo de lo anterior, conviene realizar otra distinción, ahora entre irregulares e ilegales. Seguiremos a Antonio Izquierdo para esta clasificación (Izquierdo, 1991).

- Irregular es todo extranjero que no tiene en regla su situación, pero que podría regularizarla si quisiera.

- Ilegal sería, pues, aquél que va en contra de las leyes (de extranjería, en este caso), cosa que le impide acceder a su legalización salvo en los periodos indicados por el Gobierno respectivo. 
Tabla 1. Migraciones y empobrecimiento. Riesgos de empobrecimiento.

\begin{tabular}{lll}
\hline $\begin{array}{l}\text { Desplazamiento } \\
\text { (estado como } \\
\text { referente) }\end{array}$ & $\begin{array}{l}\text { No implica } \\
\text { empobrecimiento } \\
\text { por sí mismo }\end{array}$ & $\begin{array}{l}\text { Mayor riesgo de } \\
\text { empobrecimiento } \\
\text { (absolutos) }\end{array}$ \\
\hline $\begin{array}{l}\text { Interior } \\
\text { Exterior }\end{array}$ & $\begin{array}{l}\text { Extranjero } \\
\text { Inmigrante } \\
\text { Legal } \\
\text { Regulación }\end{array}$ & $\begin{array}{l}\text { Ilegal } \\
\text { Irregular }\end{array}$ \\
\hline
\end{tabular}

Fuente: elaboración propia a partir de los autores señalados en las definiciones.

Sobre tipologías de las migraciones tenemos muchas y variadas. Una de las más conocidas (y operativas desde el punto de vista demográfico) es la que tiene en cuenta el factor geográfico del desplazamiento.

1. Migraciones internas. Son aquéllas que se producen dentro del seno de un país. Se denominan también «migraciones nacionales». En el caso de España, es muy claro el proceso migratorio de la década de los sesenta, conocido como éxodo rural y que ha ocupado innumerables páginas de estudiosos sobre el tema (Barbancho, 1982, por ejemplo).

2. Migraciones externas. También se llaman «internacionales». El carácter de estas migraciones es más complejo, en tanto que implican, un desplazamiento mayor en la distancia y en el tiempo, y las sociedades receptoras son completamente diferentes a las emisoras, lo cual provoca choques sociales y demográficos.

Como resumen de los diferentes niveles conceptuales del fenómeno migratorio, presentamos la tabla 1 .

Si atendemos a motivaciones personales, las causas de la migración son múltiples. Pero desde un punto de vista estructural, las causas fundamentales de las migraciones se pueden sintetizar en dos:

1. Motivos laborales: La búsqueda de una nueva profesión se liga a la revolución de las expectativas (Inongo Vi-Makomé, 1990) en el proceso migratorio. El norte demanda población poco cualificada, por lo que los trabajos que van a desempeñar en la sociedad receptora se insertarán en el mercado secundario. Como se ha podido constatar, en un primer momento las migraciones laborales las realiza el varón, aunque cada vez más se está produciendo un incremento de las migraciones de mujeres de esta índole (Castles, 1998). Esta circunstancia, como veremos, va a determinar los ingresos y la consideración social de estos inmigrantes.

2. Motivos políticos: Los refugiados y los exiliados son las formas clásicas de este tipo de emigración. Generalmente se producen porque en el país de origen se sucede una situación de violencia política generalizada. También desde esta perspectiva, y por seguir citando a Castles, se produce un incre- 
mento notable en las refugiadas, puesto que en las cifras del ACNUR para 1997: de todos los refugiados bielorrusos, el 65,2\% son mujeres, el 52,4\% de los refugiados en Burundi son mujeres y el 22,2\% también en Burundi, son niñas que tiene menos de cinco años (ACNUR, 1997).

Dicho de otra manera, las sociedades que expulsan población reúnen una serie de características que hacen que las podamos considerar como pobres o empobrecidas. Hay excepciones, evidentemente, y las migraciones de excelencia son un ejemplo de lo anterior. Pero en el conjunto de los países de la OCDE, los movimientos de población no son ni mucho menos de expulsión de efectivos poblacionales. Al contrario, el envejecimiento de la misma hace que tengamos que plantearnos modelos poblacionales que pasan, necesariamente, por la incorporación de efectivos provenientes de los países menos ricos. Veremos de qué manera se resuelven los elementos xenófobos y clasistas que reunimos en nuestras sociedades y si episodios como los sucedidos en El Ejido, latentes durante más de veinte años, son las formas de responder que tenemos ante la necesidad de mano de obra.

\subsubsection{Efectos generales de las migraciones. Sociedades emisoras, sociedades receptoras}

La supuesta función que cumplen las migraciones desde el punto de vista demográfico es clara: es un componente del crecimiento de la población (basta estudiar la ecuación de balance para entender esta afirmación). El saldo migratorio (que no es otra cosa que la diferencia entre emigración e inmigración), junto a las tasas de natalidad y mortalidad, forman los elementos básicos del crecimiento de la población.

Sin embargo, el peso específico en el crecimiento poblacional dependerá mucho del momento histórico que consideremos y del porcentaje que sobre la población total supone la población inmigrante. De esta forma, la migración puede suponer un auténtico alivio demográfico (es el caso español de la década de 1960, pero esta vez en relación con la migración española al extranjero) o puede ser contemplada como una auténtica amenaza por parte de la población nativa, o simplemente puede ser observada como mucho mayor a la que realmente es cuando se le pregunta a la sociedad civil. La afirmación por parte de la opinión pública es clara. Más de un 30\%, en 1995, pensaba que había "demasiados» inmigrantes. Pero si comparar es conocer, parece que la opinión pública española no está especialmente informada sobre el volumen de inmigrantes que hay en España, porque cuando se preguntaba sobre éste comparado con el de Francia (también en 1995), un 32\% de los entrevistados señalaba que había igual o mayor porcentaje de inmigrantes en España que en el país vecino ${ }^{4}$.

4. Para un análisis más detallado sobre opinión pública y migraciones en España en la década de 1990, puede consultarse el trabajo de Mateo y Zirpoli (1999). 
Dejando al margen las cuestiones de opinión pública (que no hay que descuidar, por cierto), podemos establecer algunos efectos económicos de las migraciones, tanto para los países emisores como para los receptores.

Para el país emisor, las ventajas de un proceso migratorio de expulsión de la población se pueden sintetizar en: 1) se produce un descenso de la presión demográfica sobre el mercado de trabajo, ya que los que suelen emigrar son personas en edad de trabajar. Esto permite que el trabajo en las sociedades emisoras se pueda repartir de mejor forma entre la población que resta; 2) paralelamente, el emigrante aporta divisas al país de origen, lo cual supone un impulso indirecto al desarrollo industrial.

También las migraciones aportan beneficios a los países receptores. De manera muy esquemática, éstos podrían ser: 1) por un lado, el inmigrante generalmente cobra un salario más bajo que la población autóctona, por lo que se incrementan los beneficios empresariales, que pueden ser reinvertidos; también esto permite un control de los precios y reducir las tendencias inflacionistas; 2) por otro lado, desde el punto de vista del empleo como tal, facilita la movilidad laboral de los trabajadores autóctonos debido a la flexibilidad de los primeros.

Pero lejos de ser totalmente cierto todo lo anterior, se puede decir que no todo es positivo en las migraciones. Desde un punto de vista demográfico, es posible que equilibre la población y se pueda restablecer algún tipo de economía nacional, pero desde un punto de vista más sociológico (ligado a la insatisfacción de las necesidades básicas) las migraciones tienen otro tipo de implicaciones más ligadas al proceso de empobrecimiento que otra cosa.

\subsection{Empobrecimiento, migraciones y género}

La perspectiva de género no siempre ha estado presente en los análisis de la pobreza (Tortosa, 2001). Sin embargo, desde hace ya algún tiempo, los análisis del proceso de empobrecimiento desde la perspectiva de género han empezado a hacer fortuna ${ }^{5}$. Véanse los trabajos en esta dirección del PNUD (informes sobre desarrollo humano de 1991 y de 1995), utilizándose una terminología ya clásica como feminización de la pobreza, que sigue empleándose en investigaciones de ámbito internacional (Alloo y Harcourt, 1997: 9-12; Andersen y Larsen, 1998, y, de forma más explícita, Marcoux, 1998). Podemos, de todas formas, encontrar varias aproximaciones a género y pobreza: por un lado, los primeros estudios sobre la feminización de la pobreza como una realidad mundial (Buvinic, 1997) añadiendo a los datos conocidos de pobreza la variable sexo, desglosando pues los datos entre hombres y mujeres. Así, un análisis comparado de dichos datos nos puede caracterizar la pobreza de las mujeres. La visión un poco antitética a la anterior es la que habla del proceso de empobrecimiento (o bienestar, también podemos encontrar esa acepción) y género. 
Por decirlo de otra forma, no se trata de ver que las mujeres son pobres, sino que la pobreza está condicionada por el género (Jackson, 1998: 69). Al igual que en los procesos migratorios, podemos adoptar una visión más de recuento de mujeres que emigran (feminización de las migraciones) o intentar comprender el papel del género en los movimientos de población.

Se adopte la perspectiva que se adopte, parece claro, y en palabras de la UE, que el colectivo de mujeres es uno de los grupos de riesgo susceptibles de padecer situaciones de exclusión social y procesos de empobrecimiento. Como lo es también el colectivo de inmigrantes. Y si realizamos el sumatorio de probabilidades (mujer más inmigrante) obtenemos un resultado realmente preocupante. Algunas reflexiones para el caso de España van encaminadas precisamente en esa dirección (Estefanía, 1999)

Entonces, si observamos las relaciones entre el proceso de empobrecimiento o exclusión social y los procesos migratorios (Fielding, 1997, por ejemplo) y lo relacionamos con el género (Louwerse, 1999), migraciones de las mujeres, por un lado, y, por otro, el efecto que sobre ellas tiene la migración del varón (Kofman y Sales, 1998), acabamos por entender precisamente que cuando ambos factores se juntan, las situaciones de empobrecimiento se hacen más claras.

\section{Factores de empobrecimiento de los inmigrantes en la Comunidad Valenciana}

\subsection{Primer factor: el número de inmigrantes en las sociedades desarrolladas}

Si la percepción general es que el volumen de inmigrantes y extranjeros en la sociedad receptora, en este caso la Comunidad Valenciana, es muy grande, los datos reales, una vez más, nos dicen lo contrario. La población extranjera suponía un 1,25\% sobre el total de la población de la Comunidad Valenciana (datos para 1994).

Pero quizá lo podamos entender mejor con el análisis de datos longitudinales (en particular, vamos a tomar los datos desde 1988 hasta 1997). Es interesante la comparación entre los incrementos porcentuales anuales para el conjunto del territorio español y para el de la Comunidad Valenciana (tabla 2).

Aunque los datos relativos indiquen que la población inmigrante en España se ha multiplicado desde 1988 hasta 1997 por ocho (por siete para el caso de la Comunidad Valenciana), es importante tener los números absolutos muy claros. Estos incrementos desde el punto de vista relativo son el argumento perfecto para establecer políticas de cupos a inmigrantes lo suficientemente restrictivas que eviten que el coeficiente de multiplicación de población inmigrante siga incrementándose. A todas luces, ese argumento carece de peso, puesto que las cifras de inmigrados en el tiempo tienen una característica fundamental: su irregularidad, es decir, la falta de una constante que permita ajustar las tendencias de las variaciones porcentuales en la entrada de inmigrantes como una tendencia al alza o a la baja. Las $R^{2}$ del ajuste lineal a las tendencias 
Tabla 2. Evolución absoluta (miles de personas) de los inmigrantes por comunidades autónomas (1988-1997). Variaciones anuales en términos porcentuales.

\begin{tabular}{lrrrrrrrrrr}
\hline & 1988 & 1989 & 1990 & 1991 & 1992 & 1993 & 1994 & 1995 & 1996 & 1997 \\
\hline Andalucía & 1.355 & 2.448 & 1.692 & 1.380 & 1.367 & 1.373 & 1.827 & 1.711 & 1.178 & 4.014 \\
Aragón & 125 & 132 & 156 & 182 & 147 & 117 & 81 & 86 & 36 & 168 \\
Asturias & 101 & 226 & 270 & 158 & 196 & 200 & 170 & 193 & 108 & 305 \\
Baleares & 1.388 & 1.626 & 1.594 & 1.351 & 1.805 & 584 & 695 & 610 & 681 & 984 \\
Canarias & 625 & 935 & 1.135 & 1.181 & 952 & 1.345 & 1.669 & 1.425 & 1.915 & 5.404 \\
Cantabria & 11 & 13 & 21 & 50 & 25 & 24 & 116 & 129 & 86 & 81 \\
Castilla & & & & & & & & & & \\
la Mancha & 22 & 29 & 86 & 117 & 218 & 257 & 252 & 286 & 215 & 765 \\
Castilla y León & 113 & 147 & 309 & 159 & 283 & 326 & 287 & 220 & 120 & 376 \\
Cataluña & 1.518 & 2.752 & 2.481 & 1.955 & 4.777 & 3.630 & 3.514 & 4.975 & 4.564 & 8.288 \\
Comunidad & & & & & & & & & & \\
Valenciana & 1.487 & 2.285 & 1.622 & 1.419 & 1.853 & 1.328 & 1.966 & 1.801 & 1.631 & 4.331 \\
Extremadura & 23 & 38 & 41 & 36 & 114 & 118 & 126 & 148 & 102 & 376 \\
Galicia & 397 & 522 & 679 & 493 & 410 & 239 & 362 & 357 & 221 & 880 \\
Madrid & 205 & 2.635 & 2.816 & 1.445 & 4.955 & 4.629 & 5.647 & 5.948 & 4.199 & 6.863 \\
Murcia & 80 & 167 & 171 & 137 & 373 & 474 & 971 & 498 & 726 & 1182 \\
Navarra & 156 & 255 & 351 & 251 & 447 & 330 & 342 & 474 & 349 & 333 \\
País Vasco & 180 & 201 & 277 & 218 & 276 & 376 & 500 & 612 & 491 & 1089 \\
La Rioja & 13 & 3 & 24 & 19 & 13 & 5 & 24 & 61 & 59 & 154 \\
\hline Total & 965 & 1.442 & 1.373 & 1.055 & 1.822 & 1.536 & 1.855 & 1.954 & 1.669 & 3.562 \\
\hline Incrementos & & & & & & & & & & \\
$\quad$ \% España & 0 & 33 & -5 & -30 & 42 & -19 & 17 & 5 & -17 & 53 \\
Incrementos & & & & & & & & & & \\
\% Comunidad & & & & & & & & & & \\
Valenciana & 0 & 35 & -41 & -14 & 23 & -40 & 32 & -9 & -10 & 62 \\
\hline Furat & & & & & & & & & & \\
\hline
\end{tabular}

Fuente: INE.

de estas variaciones, tanto para el caso del conjunto de España como para el de la Comunidad Valenciana, no son significativas $\left(R^{2}\right.$ España $=0,0292$; $R^{2}$ Comunidad Valenciana $\left.=0,0684\right)$. Esto significa que no hay una evidencia sobre tendencias relativas alcistas (en cuanto a incrementos porcentuales del contingente de imitados) que justifiquen el cierre de fronteras ante una hipotética avalancha de inmigrantes. Quizá haya que buscar explicaciones a las políticas en otros ámbitos o tal vez en las estructuras o coyunturas económicas.

De esta forma, el incremento de los inmigrantes, por un lado, no implica una amenaza demográfica ni económica (esto se verá más tarde) para el país de acogida. Y para los inmigrantes, el incremento de compatriotas en los lugares a los que han partido es un elemento clave para mitigar los procesos de empobrecimiento de éstos. Así parece ser que lo han visto algunas entidades políticas que promueven el reagrupamiento familiar, por ejemplo, como un tipo de políticas de integración social y mejor de la situación de vida de los inmigrantes y las inmigrantes. 
Tabla 3. Residentes extranjeros en la Comunidad Valenciana y España (1994) por continente de procedencia (\%).

\begin{tabular}{lcccccc}
\hline & Europa & América & África & Asia & Oceanía & Total \\
\hline España & 51,8 & 22,4 & 17,9 & 7,7 & 0,2 & 100 \\
Comunidad Valenciana & 74,1 & $\mathbf{1 1 , 2}$ & $\mathbf{1 0 , 3}$ & $\mathbf{4 , 2}$ & $\mathbf{0 , 1}$ & $\mathbf{1 0 0}$ \\
Alicante & 85,8 & 7,0 & 4,9 & 2,3 & 0,1 & 100 \\
Castellón & 48,6 & 12,9 & 33,2 & 5,2 & 0,2 & 100 \\
Valencia & 48,0 & 23,3 & 18,8 & 9,7 & 0,2 & 100 \\
\hline
\end{tabular}

Fuente: reelaboración propia a parir de Fambuena y Moya (1997).

Otro elemento clave para identificar qué tipo de población emigra (más que nada su condición socioeconómica) es observar la procedencia de dichas personas. En primer lugar, no toda la población extranjera tiene la denominación de «inmigrante» (en el contexto que hemos estado utilizando dicho término en este trabajo). Si observamos los datos de la tabla 3, en 1994 más del $50 \%$ de la población residente extranjera en España era europea y más de un $74 \%$ en el caso de la Comunidad Valenciana. Es presumible que estamos ante un tipo de movilidad espacial muy ligada a la doble residencia y a la estancia de placer. No es pensable que este colectivo presente situaciones de empobrecimiento severos ni moderados. Son los procesos migratorios africanos y parte de los americanos y asiáticos los que están vinculados de manera directa con los procesos de empobrecimiento.

Otra fuente para estimar el volumen de los inmigrantes que nos permita eliminar el elemento perturbador de la residencia de placer o de las migraciones de excelencia, podría ser los datos procedentes de la regularización de inmigrantes facilitados por Comisiones Obreras. Para el total de ciudades analizadas en la muestra (y atendiendo especialmente al caso de la Comunidad Valenciana) obtenemos las siguientes distribuciones porcentuales (tabla 4).

Tabla 4. Extranjeros según los datos de la regularización de 1996 (Comisiones Obreras) por procedencia ( $\%$ en columnas).

\begin{tabular}{lcccccccc}
\hline & $\begin{array}{l}\text { Norte } \\
\text { de África }\end{array}$ & $\begin{array}{l}\text { Resto de } \\
\text { África }\end{array}$ & $\begin{array}{l}\text { Asia } \\
\text { Oceanía } \\
\text { India }\end{array}$ & $\begin{array}{l}\text { Europa } \\
\text { del Este }\end{array}$ & $\begin{array}{l}\text { Resto } \\
\text { de Europa }\end{array}$ & $\begin{array}{l}\text { América } \\
\text { del Norte }\end{array}$ & $\begin{array}{l}\text { América } \\
\text { del Sur }\end{array}$ & $\begin{array}{c}\text { América } \\
\text { Central }\end{array}$ \\
\hline Alicante & 10,7 & 14,3 & 1,1 & 18,2 & 16,7 & - & 6,4 & - \\
Barcelona & 8,5 & 11,6 & 10,9 & 9,1 & 16,7 & 100,0 & 48,7 & 73,3 \\
Castellón & 1,6 & - & - & - & - & - & 6,4 & - \\
Gerona & 0,3 & - & - & - & - & - & - & - \\
Lérida & 22,8 & 0,8 & 2,2 & - & - & - & - & - \\
Logroño & - & - & 1,1 & - & - & - & - & - \\
Murcia & 12,7 & 1,9 & 1,1 & - & 16,6 & - & - & - \\
Tarragona & 2,1 & 10,9 & - & - & - & - & - & - \\
Valencia & 41,3 & 60,5 & 83,6 & 72,7 & 50,0 & - & 38,5 & 26,7 \\
\hline Total & 100 & 100 & 100 & 100 & 100 & 100 & 100 & 100 \\
\hline
\end{tabular}

Fuente: Base de Datos de CCOO sobre la regularización de 1996. Elaboración propia. 
En general, los inmigrantes procedentes de África y de países pertenecientes a la periferia del sistema económico mundial, son los que sufren en sus países de procedencia las situaciones de empobrecimiento mayores, que condicionan su partida. Sin duda, el viaje, el proceso migratorio se realiza con una motivación: superar las situaciones de empobrecimiento a las que se ven sometidos y sometidas en los países del sur. Pero, ¿en qué situación se insertan estos inmigrantes pobres (comparativamente hablando) cuando llegan a las sociedades receptoras?

\subsection{Segundo factor: empleo y situación económica. Las paradojas del empobrecimiento}

En periodos de crisis económica, la opinión pública se muestra bastante más hostil con los extranjeros. Se podía observar en 1996, cuando más de un 50\% de los españoles estaba de acuerdo con la afirmación «los inmigrantes quitan puestos de trabajo a los españoles», según el CIS. Sin embargo, paradojas de la propia opinión pública, el 78\% también estaba de acuerdo en que «los inmigrantes procedentes de países menos desarrollados desempeñan trabajos que los españoles no quieren" (mismo estudio CIS; junio de 1996). No parece claro para la opinión pública el papel económico y laboral que desempeñan los inmigrantes.

Si fuese cierta la visión más negativa sobre los inmigrantes y la sustitución de empleo (y rentas), cabría pensar, aislando al grupo de desplazados, que se produciría un empobrecimiento de las sociedades receptoras. Esto, empíricamente, no es así. Para el caso de España podemos hacer un estudio de la correlación entre volumen de inmigrantes y pobreza. Los resultados están expresados en la tabla 5.

Aunque no hay correlación entre pobreza monetaria e inmigración ( $r$ de Pearson $=-0,237$ ), cuestión que ya desmiente la afirmación "más inmigrantes, menos trabajo, luego más pobreza», sí parece que el volumen mayor de inmigrantes, la mitad concretamente en 1991 se concentraba en las cinco comunidades menos pobres. Pero si vamos un poco más allá, podemos eliminar del análisis de correlación las comunidades que tengan más del 10\% de población inmigrante. Obtenemos una distribución más homogénea, que permite observar que casi se da una relación lineal entre el número de inmigrantes y la pobreza. Esta relación es negativa. A más inmigrantes, menos pobreza $(r$ Pearson $=-0,516)$.

Respecto a los procesos de empobrecimiento de los inmigrantes, como se señaló en un principio, el inmigrante supone una manera sencilla de hacer descender los precios y los salarios (esto podría tener una vinculación con el empobrecimiento, pero sólo si en sus trabajos sustituyeran mano de obra autóctona). Pero eso no es todo. Con su incorporación al mercado secundario, los inmigrantes ilegales pueden fomentar tipos de economía sumergida, que, vinculada a la ilegalidad, les convierte en colectivo fácilmente extorsionable. Todo esto es fruto de la estructura ocupacional del país receptor y de las características del emigrado. Los inmigrantes laborales normales (los que no vienen mediante migraciones de excelencia) tienen que amoldarse a unas condiciones duras de trabajo, explotados por no tener una cualificación profesional ele- 
Tabla 5. Porcentaje de hogares bajo la línea de pobreza del 50\%, comparado con el volumen (\%) de inmigrantes por comunidad autónoma. Datos para 1991.

\begin{tabular}{lccc}
\hline Comunidades & $\begin{array}{c}\text { \% hogares pobres } \\
\text { por debajo de la línea } \\
\text { autónomas }\end{array}$ & $\begin{array}{c}\text { \% inmigrantes } \\
(\mathbf{1 9 9 1 )}\end{array}$ & $\begin{array}{c}\text { \% inmigrantes } \\
\text { acumulado }\end{array}$ \\
\hline Extremadura & 40,8 & 0,3 & \\
Andalucía & 28,5 & 13,1 & \\
Castilla y León & 27,7 & 1,5 & \\
Canarias & 26,6 & 11,2 & 28,5 \\
Murcia & 25,1 & 1,3 & \\
Castilla la Mancha & 24 & 1,1 & \\
Galicia & 23,6 & 4,7 & \\
Comunidad Valenciana & 20,8 & 13,4 & \\
Aragón & 20,4 & 1,7 & \\
Cantabria & 16,5 & 0,5 & \\
La Rioja & 15,7 & 0,2 & \\
Asturias & 12,8 & 1,5 & \\
Cataluña & 10,1 & 18,5 & \\
Baleares & 9,6 & 12,8 & \\
País Vasco & 9,6 & 2,1 & \\
Madrid & 7,4 & 13,7 & \\
Navarra & 5,2 & 2,4 & \\
Total & 19 & 100 & \\
\hline Futa & & & \\
\hline
\end{tabular}

Fuente: elaboración propia a partir de la EPF, 1991 e INE.

vada y con la amenaza de ser denunciados (si son ilegales). Así, el inmigrante es mano de obra barata que en ningún momento desplaza a la población nativa en los puestos de trabajo que ocupa: realiza actividades que los autóctonos no estarían dispuestos a realizar, luego, en términos económicos y de rentas, no implica empobrecimiento de las sociedades receptoras, sino todo lo contrario. Otra cosa es lo que sucede con el inmigrante o la inmigrante, que sí experimenta situaciones de empobrecimiento, aunque no tengan porqué ser exclusivamente económicas.

El papel económico de la mujer emigrada es más complejo. También vinculadas a sectores de la economía informal o secundaria (poca cualificación, desconocimiento del funcionamiento de la sociedad receptora, etc.), las desigualdades de género son todavía más profundas. Si aún se dan diferencias claras en la remuneración según la profesión y el trabajo desempeñado entre hombres y mujeres no inmigrantes (Robinson, 1998), mayores son estas diferencias si lo vemos desde la perspectiva de la mujer desplazada. Y aunque parece que los datos sobre ocupación de las mujeres inmigrantes no son excesivamente buenos, en situaciones de desempleo (o empleo precario exclusivamente) se tiende a incrementar las tensiones precisamente sobre el colectivo femenino 
(Sen, 1997). A todas estas cuestiones hay que sumarle una muy importante y que afecta directamente al colectivo femenino. Son los trabajos, por llamarlos así, dentro de actividades ligadas a prostitución y a otras de carácter ilegal.

Por último, la evolución de la población activa por sectores de producción en la Comunidad Valenciana sigue la evolución lógica de los países industrializados en cuanto a reducción de sus efectivos en los sectores primario y secundario y un incremento en el terciario. La construcción se mantiene, con altibajos, y se conforma como uno de los polos de desarrollo más importantes para la Comunidad. Sin embargo, si observamos en qué sectores se encuadran los trabajadores extranjeros (de los que se tiene constancia, porque otros muchos trabajan y han sido computados) obtenemos, con respecto al total de trabajadores extranjeros, una distribución peculiar. En primer lugar, el 12,1\% de éstos trabajan en el sector primario, más concretamente en la agricultura, sobre todo en la provincia de Castellón. Un 8,6\% lo hacen en la industria, un 5\% en la construcción y un 62,3\% trabajan en el sector servicios. Estos datos para 1994 nos vienen a indicar que existe una sobrerrepresentación de trabajadores inmigrantes en sectores como la agricultura (trabajos temporales centrados en la recolección) y los servicios (personales, generalmente). La provincia con mayor número de inmigrantes empleados en el sector servicios era, en 1994, Alicante ${ }^{6}$, con un $77,3 \%$. Curiosamente es la provincia que más mujeres tiene empleadas porcentualmente hablando.

Dado que la mayoría de las necesidades son satisfechas en el mercado (Casado, 1994), el nivel de renta e ingresos parece claro para poder satisfacer parte de esas necesidades. Si los colectivos inmigrantes están empleados de manera irregular y en el mercado secundario de trabajo, por fuerza sus ingresos totales son muy bajos, tan bajos que no cubrirían de manera digna la reproducción de la vida material. De esta forma, si midiésemos la pobreza sólo de manera monetaria, vía ingreso o gasto, nos encontraríamos con un colectivo realmente empobrecido y con una perspectiva de futuro no mucho mejor. Sin embargo, la amplitud del concepto de pobreza que estamos manejando permite avanzar en otros sentidos:

- La no disponibilidad de rentas dignas y adecuadas impide la satisfacción de la necesidad humana de salud física, en tanto que una nutrición deficiente puede cronificarse en una enfermedad grave.

- También porque sin rentas más o menos elevadas el acceso a otro tipo de bienes materiales considerados fundamentales es imposible. Piénsese en la vivienda, pero una vivienda equipada con agua corriente y demás elementos necesarios apta para una vida digna (Martín-Guzmán y Bellido, 1994).

- Las rentas bajas impiden el acceso a procesos de formación profesional (o mejor del capital humano). Ello está ligado con la situación de ilegalidad que veremos más tarde.

6. Un trabajo interesante sobre las empleadas inmigrantes en servicios domésticos pero para la comunidad de Murcia es el realizado por Serrano (1997). 
- Por último, la capacidad monetaria, el dinero ganado en las actividades laborales, muchas veces es enviado a los países de origen, a la familia del emigrado, cosa que agrava aún más la situación de precariedad aquí, aunque sea un gran alivio para las familias de los desplazados que se quedaron allá.

\subsection{Tercer factor: politicas y servicios sociales}

Si existe una legislación lo suficientemente severa como para no permitir ningún tipo de migración que no siga los cauces legales, el inmigrante se encontrará que, aparte de ocupar puestos de trabajo peor pagados y peor considerados socialmente, está perseguido por la justicia. Entonces, podemos considerar como otro factor clave generador de pobreza, el contexto político de la sociedades de destino que recibe al inmigrante. Varias cuestiones se desprenden de lo anterior:

- Por un lado, las políticas de inmigración suponen la legislación básica a la que se enfrentan todos los inmigrantes. Las leyes de extranjería no cumplen las características deseables de ser integrativas (buscando la permanencia de los inmigrantes en la sociedad receptora) y selectivas (específicas para los inmigrantes). Más bien al contrario. Se busca regular el número de entradas y controlar los excedentes de inmigración. Así, la legislación en materia de migraciones empobrece en sentido amplio a los inmigrantes, en particular a los ilegales. Y la Comunidad Valenciana no se libra de estas políticas.

- Sin embargo, aún es posible hablar de otro tipo de políticas que afectan a los inmigrantes, al margen de las normativas anteriores. Las politicas sociales en sentido amplio son un factor más de pobreza y que agudiza la situación del inmigrante. Con respecto a esto, las necesidades que no pueden satisfacerse con políticas sociales regresivas y no universalistas son tanto la de salud física como la de autonomía. Vayamos por partes. Si las políticas sociales no diseñan instrumentos capaces de analizar y tratar la situación de los inmigrantes manejando todas las variables (incluidas las necesidades específicas, por ejemplo, de hombres y mujeres) y se limitan simplemente a asistir, muchas veces esa asistencia queda limitada a parámetros políticos y administrativos del estilo "estar empadronado o no estarlo» para recibir la ayuda. Un ejemplo claro lo tenemos en la sanidad pública y en los debates desatados sobre si es precisa la ayuda a inmigrantes aunque no sean ciudadanos españoles ${ }^{7}$. Sin una serie de condiciones legales, los servicios sociales no pueden atender a la población inmigrante. Esto es una contradicción en sus términos, ya que las necesidades que puedan plantear los inmigrantes ilegales son, a simple vista, mayores que las que puedan presentan los legales o aquéllos que han realizado el tránsito migratorio de una manera mejor para sus intereses.

7. Para ampliar las relaciones entre salud y migraciones desde la perspectiva del empobrecimiento, se puede consultar el trabajo de Sandhaus (1998). 
Además de los factores políticos que desde la sociedad receptora influyen en el proceso de insatisfacción de necesidades de los inmigrantes y las inmigrantes, es necesario señalar que la participación política de los inmigrantes es, desde un punto de vista formal, escasa o nula. Además, esta participación política (en el caso que la hubiere y fuese diferente a la canalizada por las asociaciones de autoayuda) difiere mucho entre hombres y mujeres (Jones-Correa, 1998).

\subsection{Cuarto factor: cultura y educación. Xenofobia y racismo}

La xenofobia (el temor a lo desconocido) y el racismo como institucionalización política de la xenofobia son dos de las reacciones de autoprotección que, tanto el inmigrante como la sociedad receptora, experimentan en un primer momento. Las claves de la desintegración social y familiar debida a la ruptura de los vínculos familiares y culturales de origen (Hagan, 1998) en el inmigrante que llega a la Comunidad Valenciana están servidas. La cuestión es especialmente complicada cuando son las mujeres quienes se desplazan, pues continúan siendo el núcleo de las familias y el principal agente de socialización. Los últimos sucesos en El Ejido nos hacen pensar que las sociedades xenófobas discriminan y por lo tanto empobrecen más a los inmigrantes que acogen. Algunos datos sobre xenofobia son los realizados por el Instituto de Migraciones y Servicios Sociales para 1997 (tabla 6).

La cuestión de la lengua es otro tema, así como el choque entre diversas culturas, costumbres y ritos, que pueden acentuarse si ello va acompañado de actitudes, por ejemplo religiosas, que cuestionen las convicciones de la mayoría. Algunos elementos hay que señalar desde el punto de vista cultural del país receptor y del inmigrante que le convierten en un factor añadido para convertirse en empobrecido y empobrecida:

- Por un lado, la cultura del país receptor (en el caso español y en el caso de la Comunidad Valenciana aún más claramente) ha pasado de ser, con respecto a la inmigración, un país o comunidad de emigrantes a uno de inmigrantes. Esto tiene sus repercusiones que se traducen en una xenofobia más o menos canalizada en los actos deportivos, pero que en la vida real y social se puede también apreciar. Un ejemplo de esto sucede con el pueblo gitano, el cual lleva conviviendo con nosotros más de cinco siglos y se sigue produciendo una segregación cultural más que evidente. Pero también sucede con el senegalés que se dedica a la venta ambulante o con

Tabla 6. Índice de xenofobia por sexo. España, diciembre de 1997. Tantos por ciento calculados por filas.

\begin{tabular}{lccl}
\hline & Varones & Mujeres & Diferencias V/M \\
\hline Nada xenófobo & 51 & 49 & Similares \\
Poco xenófobo & 46 & 54 & Más mujeres \\
Algo xenófobo & 47 & 53 & Más mujeres \\
Muy xenófobo & 57 & 43 & Más hombres \\
\hline
\end{tabular}

Fuente: reelaboración propia a partir de IMSERSO (1998). 
la dominicana mal empleada en el servicio doméstico de acomodados profesionales autóctonos. Pero también se puede apreciar en el trato escolar que recibe el inmigrante y la segunda generación.

- También hay que señalar que los modelos educativos de los países receptores tienden hacia la homogeneización cultural o, como mucho, hablan de multiculturalidad, que en la práctica suele traducirse en una segregación educativa. Si bien se ha hablado mucho de la personalización del currículo del alumno, parece que la enseñanza multicultural no ha calado definitivamente en el ámbito de la escuela española. Esto provoca el proceso conocido como "asimilación cultural», que se traduce en una pérdida de diversidad cultural y en las señas de identidad del inmigrante, y con ello no se satisface la necesidad de autonomía.

- Pero, además, el inmigrante trae consigo una serie de cuestiones muy particulares que acentúan los procesos de empobrecimiento señalados más arriba. De manera sintética, éstos son: la baja cualificación educativa en su país de origen; el desconocimiento de la lengua del país al que se dirige o en el que acaba quedándose, y sus propias consideraciones personales y culturales sobre los tipos de cultura y las gentes que se encontrará en el país receptor.

\section{Conclusiones}

A modo de conclusión conviene sistematizar algunas de las cuestiones expuestas en las páginas anteriores. En primer lugar, parece claro que existe una relación entre el tipo de migración que se produce y las situaciones de pobreza o de empobrecimiento (Fielding, 1997), de tal manera que las migraciones de excelencia no son susceptibles de producir, en sentido estricto, pobreza, al menos entendida ésta como algo material. Sí se observan diferencias de género incluso en migraciones de excelencia (Bernstein y Shuval, 1999), cosa que nos hace pensar que entre la pobreza y la migración hay un tercer elemento que describe y puede explicar los dos primeros: el género.

En segundo lugar, e incorporando la perspectiva de género para el análisis del proceso de empobrecimiento, tanto la feminización de la pobreza (la visión "pobres entre los pobres» o "mujeres pobres» (Lipton, 1997)) como otra visión más cercana a las cuestiones de género y desarrollo o género y pobreza (Jackson, 1998; Cagatay, 1998), confirmamos que existe una relación muy clara entre los procesos de empobrecimiento y el género. Precisamente, éstos últimos son más claros en el colectivo femenino debido a una desigualdad de oportunidades vitales, a una conceptualización cultural del género femenino que sienta las bases precisamente de la desigualdad (en esa dirección se pueden ver los trabajos de Martha Nussbaum, por ejemplo) y a una determinada manera de entender la sociedad y las relaciones desde una perspectiva materialista.

En tercer lugar, la combinación de diferentes cuestiones dentro del proceso migratorio empobrecen, en mayor o menor medida, al emigrante, máxime si se trata de emigradas. Una propuesta de factores de empobrecimiento desde la perspectiva de género se presenta en la tabla 7 . 
Tabla 7. Migraciones y factores de empobrecimiento desde la perspectiva de género.

\begin{tabular}{|c|c|c|c|c|}
\hline & País emisor & País receptor & $\begin{array}{l}\text { Naturaleza del } \\
\text { vínculo con procesos } \\
\text { de empobrecimiento }\end{array}$ & $\begin{array}{l}\text { Procesos de } \\
\text { empobrecimiento } \\
\text { (necesidades insatisfechas) }\end{array}$ \\
\hline \multirow[b]{2}{*}{$\begin{array}{l}\text { Procesos } \\
\text { demográficos }\end{array}$} & $\begin{array}{l}\text { Expulsión de } \\
\text { población en } \\
\text { edad de trabajar. } \\
\text { Desequilibrio } \\
\text { poblacional. }\end{array}$ & $\begin{array}{l}\text { Incorporación } \\
\text { de efectivos } \\
\text { poblacionales en } \\
\text { edad de trabajar. } \\
\text { Equilibrio. }\end{array}$ & Indirecta. & $\begin{array}{l}\text { Viaje. } \\
\text { Pérdida de referentes } \\
\text { familiares. }\end{array}$ \\
\hline & $\begin{array}{l}\text { Expulsión de } \\
\text { varones. La } \\
\text { mujer no tiene } \\
\text { oportunidades } \\
\text { de migrar si } \\
\text { no es para } \\
\text { reencuentro. }\end{array}$ & $\begin{array}{l}\text { Incremento de las } \\
\text { migraciones de } \\
\text { mujeres (tendencia } \\
\text { global). } \\
\text { Desequilibrio. }\end{array}$ & Indirecta. & $\begin{array}{l}\text { No viaje. } \\
\text { Permanencia en sociedades } \\
\text { pobres. }\end{array}$ \\
\hline & $\begin{array}{l}\text { Economías menos } \\
\text { desarrolladas. } \\
\text { Incorporación } \\
\text { de divisas. }\end{array}$ & $\begin{array}{l}\text { Mano de obra barata. } \\
\text { Revitalización de } \\
\text { algunos sectores } \\
\text { económicos. }\end{array}$ & Directa, indirecta. & $\begin{array}{l}\text { No trabajo. Cuando trabajan, } \\
\text { no regulación. } \\
\text { Rentas bajas y desiguales. }\end{array}$ \\
\hline $\begin{array}{l}\text { Estructuras } \\
\text { económicas }\end{array}$ & $\begin{array}{l}\text { Mujer como } \\
\text { elemento } \\
\text { productor y } \\
\text { reproductor } \\
\text { de la familia. }\end{array}$ & $\begin{array}{l}\text { Mano de obra barata. } \\
\text { Empleo precario en } \\
\text { sectores como el } \\
\text { servicio doméstico. } \\
\text { Objeto de abusos } \\
\text { y actividades } \\
\text { delictivas. } \\
\text { Prostitución, trata } \\
\text { de blancas. }\end{array}$ & $\begin{array}{l}\text { Directa, } \\
\text { muy intensa. }\end{array}$ & $\begin{array}{l}\text { No trabajo. Cuando trabajan, } \\
\text { no regulación. } \\
\text { Rentas bajas y desiguales. } \\
\text { Prostitución. }\end{array}$ \\
\hline \multirow{2}{*}{$\begin{array}{c}\text { Estructuras } \\
\text { políticas }\end{array}$} & $\begin{array}{l}\text { Violencia política. } \\
\text { Contextos no } \\
\text { democráticos. }\end{array}$ & $\begin{array}{l}\text { Políticas de } \\
\text { extranjería. Políticas } \\
\text { de cupos. Servicios } \\
\text { sociales no } \\
\text { universales. } \\
\text { No ciudadanía. }\end{array}$ & Directa. & $\begin{array}{l}\text { Ilegal, irregular. } \\
\text { No participación política. } \\
\text { No atención sanitaria. }\end{array}$ \\
\hline & $\begin{array}{l}\text { Violencia política. } \\
\text { Contextos no } \\
\text { democráticos. }\end{array}$ & $\begin{array}{l}\text { Políticas de } \\
\text { extranjería. Políiticas } \\
\text { de cupos. Servicios } \\
\text { sociales no } \\
\text { universales. } \\
\text { No ciudadanía. }\end{array}$ & Directa. & $\begin{array}{l}\text { Ilegal, irregular. } \\
\text { No participación política. } \\
\text { No atención sanitaria. }\end{array}$ \\
\hline \multirow[b]{2}{*}{$\begin{array}{c}\text { Estructuras } \\
\text { culturales }\end{array}$} & $\begin{array}{l}\text { Migración como } \\
\text { algo negativo. }\end{array}$ & $\begin{array}{l}\text { Xenofobia. Rechazo. } \\
\text { Proceso de } \\
\text { asimilación cultural. }\end{array}$ & Directa. & $\begin{array}{l}\text { Problemas de identidad. } \\
\text { Falta de referentes culturales. } \\
\text { Problemas de comunicación. }\end{array}$ \\
\hline & $\begin{array}{l}\text { Dominación de la } \\
\text { mujer por parte } \\
\text { del varón. }\end{array}$ & $\begin{array}{l}\text { Xenofobia. Rechazo. } \\
\text { Proceso de } \\
\text { asimilación cultural. } \\
\text { Marginación } \\
\text { específica por } \\
\text { cuestiones de sexo. }\end{array}$ & Directa, intensa. & $\begin{array}{l}\text { Problemas de identidad. } \\
\text { Falta de referentes culturales. } \\
\text { Problemas de comunicación. } \\
\text { Discriminación sexual. }\end{array}$ \\
\hline
\end{tabular}

Las filas bajo la línea punteada señalan los distintos procesos y factores desde la perspectiva de género. Elaboración propia. 
Aunque no argumentemos en la dirección de pasadas y no por ello menos vigentes aportaciones (Alonso Torrens, 1989) sobre el conjunto y sumatorio de cuestiones que hacen que las personas no puedan desarrollarse, sí existe un conjunto de probabilidades que, combinadas, ofrecen procesos y situaciones de exclusión social más que evidentes. Éste es el caso de ser mujer marroquí en Alicante, en los inicios del nuevo siglo.

\section{Bibliografía}

Abercrombie, Nicholas et al. (1986). Diccionario de Sociología. Madrid: Cátedra. ACNUR (1997). La situación de los refugiados en el mundo. Barcelona: Icaria.

Aguiar, F. (1996). «Teorías de las necesidades: una tipología». Revista Internacional de Sociología, 13, p. 135-146.

AlloO, F.; HarCourT, W. (1997). «From the South to the North: evolving perspectives on gender and poverty». Gender and development, vol. 5, núm. 3, p. 9-17.

AlONSO TORRENTS, F.J. (1989). «La acumulación de indicadores sociales de malestar y bienestar en los dos extremos de la escala de estratificación de la sociedad». Documentación Social, 76, p. 93-100.

ANDERSEN, J.; LARSEN, J. (1998). «Gender, poverty and empowerment». Critical social policy, 55, p. 241-258.

AÑON ROIG, M.J. (1994). Necesidades y derechos. Un ensayo de fundamentación. Madrid: Centro de Estudios Constitucionales.

AtKinson, A.B. (1988). «Acerca de la medida de la pobreza». ICE, 2121, del 15 al 21 de febrero.

Barbancho, A. (1982). Población, empleo y paro. Madrid: Pirámide.

BERNSTEIN, J.; SHUVAL J. (1999). "Gender differences in the process of occupational integration of immigrant physicians in Israel». Sex Roles, vol. 40 (1-2), p. 1-23.

BODEGA, M.I.; CEBRIÁN, J.A. (1995). «Una lectura económica de algunas migraciones contemporáneas. El caso de España». Estudios geográficos, 56, p. 665-694.

BOUZADA FERNÁNDEZ, Xan (1994). «Sobre las necesidades sociales y culturales: entre la necesidad constatada y la necesidad construida». Papers, 44, p. 53-76.

BunIVIC, Mayra (1997). «Women in poverty: a new global underclass». Foreing Policy, vol. 0, 108, p. 38-53.

Cagatay, N. (1998). "Gender and poverty». UNPD, Working Paper, 5, mayo.

CASADO, D. (1994). Introducción a los Servicios Sociales. Madrid: Popular.

CASAdo Díaz, J.M.; Simón PÉRez, H. (1996). Una aproximación a los fenómenos migratorios mundiales. Alicante: Universidad de Alicante.

CASTLES, S. (1998). "Globalización y migración: algunas contradicciones urgentes». Revista Internacional de Ciencias Sociales, 156, junio.

CCEE, COMITÉ ECONÓMICO y SOCIAL (1989). Documento informativo de la sección de asuntos sociales, familia, educación y cultural sobre la pobreza. Mimeo.

- (1993). Dictamen del Comité Económico y Social sobre la exclusión social. Mimeo.

CONSEIL DE L'EUROPE (1983). Les inmigrants et le développement culturel dans les villes européennes. Estrasburgo: Conseil de la Coopération Culturelle.

Dorsch, F. (1985). Diccionario de Psicología. Barcelona: Herder.

Doyal, Len; Gough, Ian (1994). Teoría de las necesidades humanas. Barcelona: Icaria/FUHEM.

Estefanía, J. (1999). «Paro: mujeres o inmigrantes». El País, 9 de mayo. 
Fambuena, A.; Moya, J. (1997). Movimientos migratorios hoy. Aproximación a la Sociología de las migraciones. Valencia: Nau Llibres.

Ferrater Mora, José (1983). Diccionario de Filosofía de bolsillo. Vol. 2. Madrid: Alianza, p. 551-555.

FIELDING, T. (1997). «Migration and poverty. A longitudinal study of relationship between migration and social mobility in England and Wales». IDS Bulletin, vol. 28, núm. 2, p. 44 y s.

García España, E. (1993). Perspectiva criminológica de la ilegalidad de los extranjeros en España: internamiento en centros de detención. Málaga: Universidad de Málaga.

GarCía MarTín, M. et al. (1997). Aproximación a las nuevas migraciones. Entre la inmigración y la cooperación al desarrollo. Valencia: Nau Llibres.

GINER, S.; SALCEDO, J. (1976). «Un vacío teórico: la explicación causal de la migración». Agricultura y sociedad, 1, p. 113-125.

GozÁlVEz PÉREZ, V. (1995). Inmigrantes marroquies y senegaleses en la España Mediterránea. Valencia: Generalitat Valenciana.

Gregorio GiL, Carmen (1998). Migración femenina. Su impacto en las relaciones de género. Madrid: Narcea.

GUIDI, M. (1993). «¿Es realmente la migración una estrategia de supervivencia? Un ejemplo en la mixteca alta oaxaqueña». Revista internacional de Sociología, 5, p. 89-109.

HAGAN, J.M. (1998). «Social networks, gender and inmigrant incorporation: Resources and constraints». American Sociological Review, 63, 1, p. 55-67.

Heller, Agnes (1978). Teoría de las necesidades en Marx. Barcelona: Península.

InSTITUTO ESPAÑOl DE EMIGRACIÓN (1972). Panorámica de la emigración. Madrid: IEE.

Instituto De Migraciones y Servicios Sociales (1998). Actitudes hacia los inmigrantes. Madrid: Ministerio de Trabajo y Asuntos Sociales.

IZQUIERDO EsCRIBANO, A. (1991). «La inmigración ilegal en España (análisis de la operación extraordinaria de regularización 1985-1986)». Revista de Economía y Sociología del trabajo, marzo.

JACKSON, C. (1998). "Women and poverty or Gender and Well-being». Journal of International Affairs, 52, 1, p. 67-81.

JONES-CORREA, M. (1998). «Different paths: gender, migration and political participation». International Migration Review, 32, núm. 2, p. 326-349.

KOFMAN, E.; SALES, R. (1998). «Migrant women and exclusion in Europe». European Journal of Women's Studies, 5, núm. 3-4, p. 381 y s.

LA COMBA, J.; ROYO, I. (1997). «Una inmigración entre la precariedad y la exclusión: condiciones de vida de los inmigrantes marroquíes y senegaleses en situación irregular en el área urbana de Valencia». Revista de Servicios Sociales y Política Social, 37, p. 93-107.

Lalame, Paulette; Lalame, Pierre (1972). Trabajadores extranjeros en Francia. Madrid: Zero.

LiPTON, M. (1997). «Editorial. Poverty: are there holes in the consensus?». World Development, 25 , núm. 7.

LOUWERSE, H, (1999). "Gender and Migration». Journal of Gender Studies, vol. 8, núm. 1, p. 105-107.

MALGeSINI, G. (comp.) (1998). Cruzando fronteras: Migraciones en el sistema mundial. Barcelona: Icaria.

Marcoux, A. (1998). "The feminization of poverty: claims, facts and data needs». Population and Development Review, vol. 24, núm. 1, p. 131-139. 
Marcuse, H. (1969). El hombre unidimensional. Barcelona: Seix-Barral.

Martín-GuZmán, P.; Bellido, N. (1994). «El equipamiento de los hogares como indicador de pobreza: un análisis basado en la encuesta de presupuestos familiares». Documentación Social, 96, p. 127-142.

MarTín Mateo, Ramón (1996). Manual de Derecho Administrativo. Madrid: Trivium.

MASLOW, A. (1979). El hombre autorrealizado. Hacia una psicología del ser. Barcelona: Kairós.

Mateo Pérez, M.A.; Zirpoli Tesouro, D. (1999). Sentimiento europeo y actitudes frente a las migraciones en España. Alicante: OBETS-Universidad de Alicante.

- (2001). «Desigualdad, pobreza y exclusión: conceptos, medidas y alternativas metodológicas». En TORTOSA, José María (coord.) (2001). Pobreza y perspectiva de género. Barcelona: Icaria.

Mateo Pérez, M.A.; Penalva Verdú, P. (2000). «Per al mesurament de la desigualtat, pobresa i exclusió. Limitaciós, propostes técniques i alternatives». Revista Catalana de Sociologia, 11.

MAX-NEEF, M. (1994). Desarrollo a escala humana. Barcelona: Icaria.

PAJARES, Miguel (1998). La inmigración en España. Madrid: Icaria.

Parada, Ramón (1995). Derecho administrativo. Madrid: Marcial Pons.

Robinson, D. (1998). «Diferencias de remuneración entre los sexos según la profesión». Revista Internacional del Trabajo, vol. 117, núm. 1.

Rubí i MarTínez, C. (1991). «El análisis de las necesidades y recursos desde la perspectiva del trabajo social». Revista de Servicios Sociales y Política Social, 21, 1er trimestre, p. 7-18.

SAGARRA I TRIAS, E. (1991). Los derechos fundamentales y las libertades públicas de los extranjeros en España. Barcelona: J.M. Bosch.

SandHaus, S. (1998). "Migrant Health. A Harvest of Poverty». American Journal of Nursing, vol. 98, núm. 9, p. 52 y s.

SANTAMARÍA, E. (1997). «Discurso, género e inmigración». Archipiélago, 30, p. 40-46.

SEN, A.K. (1997). «Desigualdad y desempleo en la Europa contemporánea». Revista Internacional del Trabajo, vol. 118, núm. 2.

SERRANO, J.M. (1997). «La actitud laboral de las mujeres magrebíes inmigrantes en la región de Murcia. Empleos en el servicio doméstico». Anales de historia contemporánea, 13, p. 141-163.

SolÉ, Carlota (1988). Catalunya: societat receptora d'immigrants. Anàlisi comparativa de dues enquestes. Barcelona: Institut d'Estudis Catalans.

TORTOSA, José María (1993). La pobreza capitalista. Madrid: Tecnos.

- (coord.) (2001). Pobreza y perspectiva de género. Barcelona: Icaria.

Vi-MAKOMÉ, INONGO (1990). España y los negros africanos. Barcelona: La Llar del Llibre.

WeEKS, John R. (1984). Sociología de la población. Madrid: Alianza Universidad. 